www.jmscr.igmpublication.org

Impact Factor 5.84

Index Copernicus Value: 71.58

ISSN (e)-2347-176x ISSN (p) 2455-0450

crossref DOI: _https://dx.doi.org/10.18535/jmscr/v5i9.108

Journal Of Medical Science And Clinical Research

\title{
A Comparison of Intraperitoneal Instilllation of Bupivacaine - Tramadol with Bupivacaine - Magnesium Sulphate for Pain Relief after Laparoscopic Cholecystectomy
}

\author{
Authors \\ Dr Syed Ali Aasim ${ }^{1}$, Dr K.Anil Kumar ${ }^{2}$, Dr Ganesh Suram ${ }^{3}$ \\ ${ }^{1}$ Professor \& HOD, Department of Anesthesiology, Chalmeda Anandrao Institute of Medical Sciences \\ Bommakal Village, Karimnagar District, Telangana State, India \\ ${ }^{2}$ Assistant Professor, Department of Anesthesiology, Chalmeda Anandrao Institute of Medical Sciences \\ Bommakal Village, Karimnagar District, Telangana State, India \\ ${ }^{3}$ Post Graduate Student, Department of Anesthesiology, Chalmeda Anandrao Institute of Medical Sciences \\ Bommakal Village, Karimnagar District, Telangana State, India \\ Correspondence Author \\ Dr Ganesh Suram \\ Post Graduate Student, Department Of Anesthesiology, Chalmeda Anandrao Institute Of Medical Sciences \\ Bommakal Village, Karimnagar District, Telangana State, India
}

\section{ABSTRACT}

Background: Recently the use of local anaesthetics, instilled intraperitoneally, alone or mixed with other drugs, after laparoscopic cholecystectomy to reduce post operative analgesia is attaining popularity.

Aims and Objectives: To compare the quality and duration of post-operative analgesia using intraperitoneal Bupivacaine plus Tramadol (BT) and Bupivacaine plus Magnesium sulfate (BM) in patients operated for laparoscopic cholecystectomy.

Materials and Methods: We carried out a prospective, randomised, double-blind study in 50 patients aged between 20 to 45 years undergoing laparoscopic cholecystectomy with ASA grade 1 and 2. They were randomly divided into two groups of 25 each, Group BT: were given $0.25 \% 30 \mathrm{ml}$ bupivacaine and $100 \mathrm{mg}$ tramadol and Group BM: were given 0.25\% 30ml bupivacaine and $50 \mathrm{mg} \mathrm{MgSO4.} \mathrm{The} \mathrm{parameters} \mathrm{assessed}$ and compared were the analgesic efficacy. duration of pain relief and associated side effects.

Results: We found more number of females than males, but difference was not statistically significant difference $(P>0.05)$. We did not find any statistically significant difference between the groups with respect to the duration of anaesthesia $(P>0.05)$. We found that the post operative pain relief was 1 to 2 hours more for BM group compared to BT group, the difference being statistically significant. We found that no side effects occurred in patients of both groups except nausea and vomiting in two patients in BT group which was statistically not significant $(\mathrm{P}>0.05)$.

Conclusion: Intraperitoneal instillation of Bupivacaine-MgS04 combination provides good analgesia in first 24 hours after surgery, with longer duration of pain free period when compared to Bupivacaine-Tramadol combination,

Keywords: Bupivacaine, Cholecystectomy, Intraperitoneal, Magnesium Sulphate, Tramadol. 


\section{Introduction}

For analgesia, intraperitoneal instillation of local anaesthetics and opioids in laparoscopic surgeries is attaining recognition. There is a major variation in the quality of pain associated with laparoscopic cholecystectomy and laparotomy. It is observed that the pain after laparotomy is mainly parietal in nature, while it is more of visceral pain after laparoscopic cholecystectomy. Usually, the pain after laparoscopic cholecystectomy was found to be extremely unpredictable in intensity and also in duration. $^{1-3}$

Magnesium Sulphate $\left(\mathrm{MgSO}_{4}\right)$ has an antinociceptive action and this is utilized by anaesthetists in cases of chronic pain, as it manages the duration and intensity of postoperative pain. Tramadol has also been shown to have a local action when administered intraperitoneally after laparoscopic surgery. ${ }^{3-5}$

Few studies have been carried out to find about the effectiveness of local anaesthetics, instilled intraperitoneally, alone or mixed with other drugs, after laparoscopic cholecystectomy. But still there is no consensus concerning the dose, concentration, site and manner of administration. ${ }^{6}$

We carried out this study to compare the quality and duration of post-operative analgesia using intraperitoneal Bupivacaine plus Tramadol (BT) and Bupivacaine plus Magnesium sulfate (BM) in patients operated for laparoscopic cholecystectomy.

\section{Materials and Methods}

We carried out a prospective, randomised, doubleblind study after obtaining institutional ethics committee approval. Our study included 50 patients aged between 20 to 45 years undergoing laparoscopic cholecystectomy with ASA grade 1 and 2. All the patients were explained in detail about the study and written informed consent was obtained from them. They were randomly divided into two groups of 25 each.

1. Group BT: were given $0.25 \% \quad 30 \mathrm{ml}$ bupivacaine and $100 \mathrm{mg}$ tramadol
2. Group BM: were given $0.25 \% \quad 30 \mathrm{ml}$ bupivacaine and $50 \mathrm{mg} \mathrm{MgSO} 4$.

A meticulous pre-anaesthetic evaluation was carried out on all the patients. Systematic randomised allocation method was followed. This was a blind study as an anaesthesiologist not involved in the conduct of anaesthesia instilled the study drugs into the peritoneal cavity, whereas another anaesthesiologist did the data collection and analysis. The patients were well-informed about the visual analogue scale (VAS) pain score of $0-10$, which was used to assess pain. Haemodynamic variables and side effects were also noted and compared at different time points. The key outcome was to compare the analgesic efficacy and duration of pain relief.

\section{Inclusion Criteria}

1. Patients undergoing laparoscopic cholecystectomy,

2. Patients of ASA grade 1 and 2 and

3. Patients aged between 20 to 45 years.

\section{Exclusion Criteria}

1. Patients with allergy to the study drugs ( $\mathrm{MgSO}_{4}$, bupivacaine and tramadol),

2. Chronic alcoholics,

3. Patients with heart block or renal failure and

4. Patients with peritoneal drain after surgery.

Standard monitoring was done with pulse oximetry, blood pressure, end-tidal $\mathrm{CO}_{2}$ and threelead electrocardiogram. General anaesthesia was given with intravenous (IV) lignocaine $1.0 \mathrm{mg} / \mathrm{kg}$, fentanyl $2.0 \mu \mathrm{g} / \mathrm{kg}$ and propofol $2.0 \mathrm{mg} / \mathrm{kg}$. IV vecuronium $0.1 \mathrm{mg} / \mathrm{kg}$ was used to facilitate endotracheal intubation. Isoflurane along with $50 \%$ oxygen in air and positive pressure ventilation was used to maintain anesthesia. Later on the instillation of the study drugs into the peritoneal cavity was carried out through laparoscopic ports guided by the surgical camera. In the postoperative room, when the patients were fully awake and responding to vocal commands, VAS pain score was recorded at 1,2,4,6,8,12 and 24 hours after surgery. The time duration of the first demand for analgesia and total paracetamol consumption in 24 hours was recorded. 


\section{JMSCR Vol||05||Issue||09||Page 28015-28020||September}

Heart rate (HR), systolic blood pressure (SBP) and diastolic blood pressure (DBP) were recorded 5 minutes before induction (i.e., baseline parameters) and subsequently every 5 minutes for the first 20 minutes after the administration of study drugs. The side effects of the studied drugs like nausea, vomiting (NV), loss of tendon reflexes and hypotension were also observed during post-operative period at intervals of 30 minutes, 40 minutes, 1 hour, 2, 4 and 6 hours after shifting to recovery room.

Statistical analysis was performed with SPSS for Windows: IBM Corp. Version 20.0. Armonk, NY, USA. Significance test was done with independent samples t-test. Results were displayed as mean \pm standard deviation, and for all statistical tests, $\mathrm{P}<$ 0.05 was considered statistically significant.

\section{Results}

When demographics were compared between two groups, they were comparable in terms of age, gender, weight and height. We found more number of females than males, but difference was not statistically significant difference $(\mathrm{P}>0.05)$. We did not find any statistically significant difference between the groups with respect to the duration of anaesthesia $(\mathrm{P}>0.05)$ (Table 1, Graph $1)$.

Table 1: Demographic profile, duration of surgery and anaesthesia in two groups

\begin{tabular}{|l|c|c|c|}
\hline Parameter & Group BT $(\mathrm{n}==25)$ & Group BM $(\mathrm{n}==25)$ & P value \\
\hline Age in years & $37.84 \pm 6.32$ & $38.69 \pm 6.45$ & 0.6400 \\
\hline Sex (Males/Females) & $12 / 13$ & $11 / 14$ & $>0.05$ \\
\hline Duration of Surgery (minutes) & $53.61 \pm 5.48$ & $51.98 \pm 7.13$ & 0.3693 \\
\hline Duration of Anaesthesia (minutes) & $72.98 \pm 4.09$ & $73.56 \pm 5.07$ & 0.6527 \\
\hline
\end{tabular}

Graph 1: Demographic profile, duration of surgery and anaesthesia in two groups

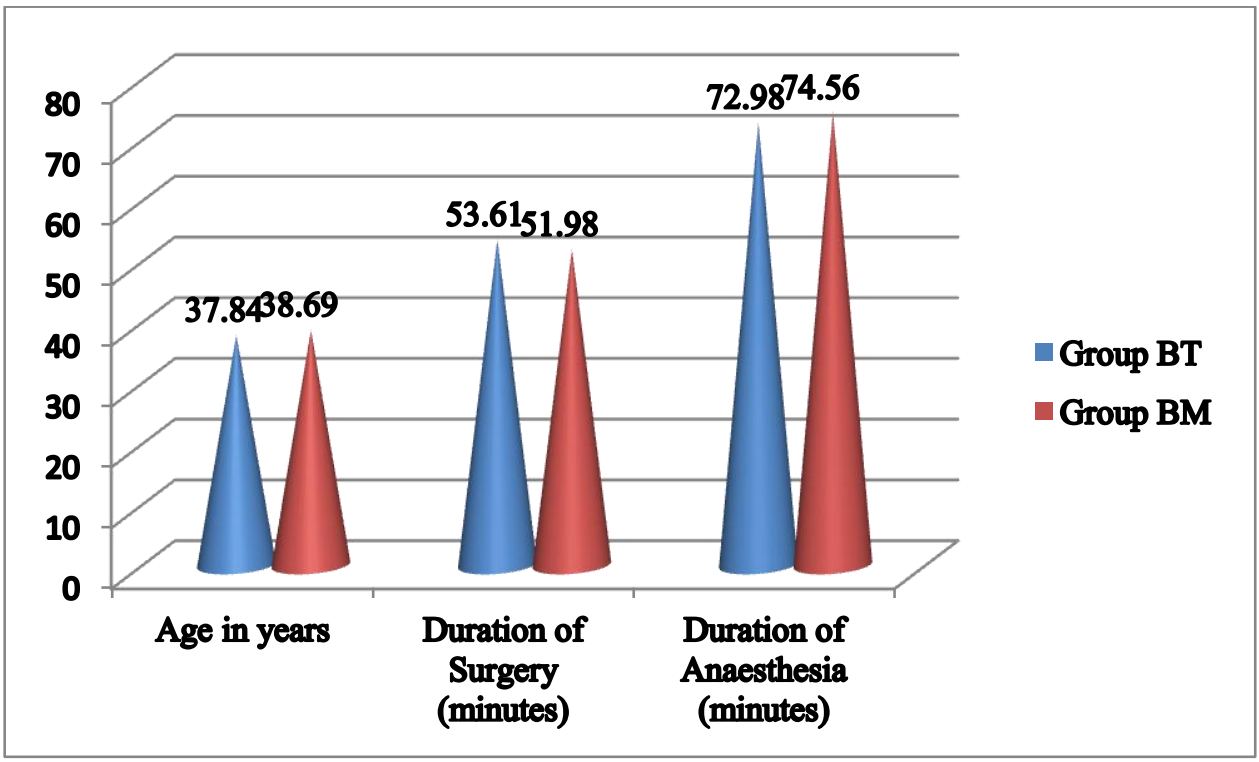

We found that the post operative pain relief was 1 to 2 hours more for $\mathrm{BM}$ group compared to $\mathrm{BT}$ group, the difference being statistically significant (Table 2).

Table 2: Visual analogue scale pain score at different time intervals in the two groups

\begin{tabular}{|l|c|c|c|}
\hline VAS & Group BT $(\mathrm{n}==25)$ & Group BM $(\mathrm{n}==25)$ & P value \\
\hline 1 Hour & $3.52 \pm 2.75$ & $1.89 \pm 1.13$ & 0.0086 \\
\hline 2 Hours & $3.92 \pm 2.31$ & $2.69 \pm 1.25$ & 0.0234 \\
\hline 4 Hours & $4.95 \pm 2.52$ & $2.12 \pm 1.58$ & $<0.0001$ \\
\hline 6 Hours & $2.98 \pm 1.41$ & $2.16 \pm 1.24$ & 0.0339 \\
\hline 8 Hours & $2.65 \pm 1.09$ & $1.69 \pm 1.54$ & 0.0142 \\
\hline 12 Hours & $2.96 \pm 1.67$ & $2.04 \pm 1,56$ & 0.0498 \\
\hline 24 Hours & $2.32 \pm 1.12$ & $1.66 \pm 1.02$ & 0.0343 \\
\hline
\end{tabular}


SBP was recorded at 5 minutes interval in both groups after the intraperitoneal instillation of study drugs. When SBP during the observation period was compared with baseline SBP, the difference was found to be statistically insignificant $(\mathrm{P}>0.05)$.

Similarly DBP was also recorded at 5 minutes interval in both groups and DBP during the observation period was compared with baseline DBP, the difference was found to be statistically insignificant $(\mathrm{P}>0.05)$.

Complaints of side effects like nausea, vomiting, loss of tendon reflexes and haemodynamical abnormalities like hypotension were recorded during post-operative period at intervals of 30 minutes, 40 minutes, 1 hour, 2, 4 and 6 hours after shifting to recovery room. We found that no side effects occurred in patients of both groups except nausea and vomiting in two patients in BT group which was statistically not significant $(\mathrm{P}>0.05)$.

\section{Discussion}

Laparoscopic cholecystectomy when compared to open cholecystectomy has several advantages like decreased postoperative pain and the need for postoperative analgesia, shortened hospital stay. Still in order to increase the success rate of outpatient laparoscopic cholecystectomy, improved post-operative analgesia, using opioidsparing regimens was suggested as both pain and opioids may induce nausea. ${ }^{7}$ For obtaining analgesia, traditionally analgesics were given parenterally. Recent studies have shown that instillation of local anaesthetics and opioids intraperitoneally showed better pain relief with minimal side effects and this is gaining popularity. ${ }^{1,2}$

The underlying mechanism of attaining analgesia by instillation of local anaesthetics intraperitoneally around the operative site is thought to be the obstruction of conduction from visceral sites, thus lessening of the intensity of referred pain. ${ }^{8}$ Other factor contributing for analgesia might be the absorption from the large peritoneal surface into systemic circulation. ${ }^{9}$ There is a contradictory opinion about when to administer the local anaesthetic. Few authors suggested for early instillation of intraperitoneal local anaesthetics as it provides better control of post-operative pain when compared with instillation at the end of the surgery, but few others have contradicted this and suggested otherwise. ${ }^{9,} 10$

The underlying mechanism of attaining analgesia by $\mathrm{MgSO} 4$ is thought to be due to the reduction of calcium influx to the cell by magnesium. Magnesium also antagonises N-methyl-D-aspartate (NMDA) receptors, which are critical for neuronal signalling as well as pain processing in the central nervous system, thus reducing post-operative pain as both somatic and visceral pain fibres are blocked. ${ }^{9} \quad$ Conventionally in laparoscopic cholecystectomy, $\mathrm{MgSO} 4$ is given in various routes such as an IV bolus, continuous infusion, epidural infusion and in the subarachnoid space. Recently it has been shown that intraperitoneal local anaesthetics alone or in addition to $\mathrm{MgSO} 4$ improved post-operative pain after laparoscopic cholecystectomy. ${ }^{1-3}$

In our study, we compared the quality and duration of post-operative analgesia using intraperitoneal Bupivacaine plus Tramadol (BT) and Bupivacaine plus Magnesium sulfate (BM) in patients operated for laparoscopic cholecystectomy.

We found that patients in BM group showed a decreased post-operative pain in first 24 hours after surgery along with longer pain-free period compared to patients in BT group after laparoscopic cholecystectomy. Our findings are in accordance with Maharjan SK et al. They compared intraperitoneal instillation of bupivacaine, solely and in addition to $\mathrm{MgSO} 4$ in a dose of $50 \mathrm{mg} / \mathrm{kg}$ and found that the patients receiving intraperitoneal bupivacaine with $\mathrm{MgSO} 4$ at the end of the surgery had better pain relief for a period of 2-5 hours compared with patients who were given only intraperitoneal bupivacaine. ${ }^{11}$ Buyukakilli B et al carried out a study on frog sciatic nerves and found a better conduction block 
with $\mathrm{MgSO} 4$ plus bupivacaine but not with Tramadol and bupivacaine. ${ }^{12}$

Akinci SB et al compared the effectiveness of tramadol given IV and intraperitoneally regarding the post operative analgesia after laparoscopic cholecystectomy and found that IV tramadol produced a better post-operative analgesia than intraperitoneal dose of tramadol. ${ }^{13}$ Shukla U et al compared the effectiveness of bupivacaine alone, bupivacaine with tramadol and intraperitoneal instillation of bupivacaine in combination with dexmedetomidine. They found that intraperitoneal instillation of bupivacaine in combination with dexmedetomidine to be superior than other two in reducing post operative pain. ${ }^{14}$

We also found that the addition of $\mathrm{MgSO} 4$ to bupivacaine decreased the heart rate slightly less than baseline and became stable thereafter when compared to patients who were given bupivacaine and tramadol after laparoscopic cholecystectomy. Our findings are in agreement with that of Jee D et al. $^{15}$

We recorded nausea and vomiting in two patients in the BT group but not in any patient in the BM group, the difference being statistically insignificant. Our findings are in accordance with that of Mentes $\mathrm{O}$ et al. According to them MgSO4 blocks NMDA receptors found in emetic pathways and structures related with the final common pathway for vomiting. ${ }^{16}$

\section{Conclusion}

lntraperitoneal instillation of Bupivacaine-MgS04 combination provides good analgesia in first 24 hours after surgery, with longer duration of pain free period when compared to BupivacaineTramadol combination, with almost no side effects in both the groups.

\section{References}

1. Yadava A, Rajput SK, Katiyar S, Jain RK. A comparison of intraperitoneal bupivacaine-tramadol with bupivacainemagnesium sulphate for pain relief after laparoscopic cholecystectomy: A prospective, randomised study. Indian Journal of Anaesthesia. 2016;60(10):757-762.

2. Golubovic S, Golubovic V, CindricStanancin M, Tokmadzic VS. Intraperitoneal analgesia for laparoscopic cholecystectomy: Bupivacaine versus bupivacaine with tramadol. Coll Antropol 2009;33:299-302.

3. Bisgaard T. Analgesic treatment after laparoscopic cholecystectomy: A critical assessment of the evidence. Anesthesiology 2006;104:835-46.

4. Shoeibi G, Sadegi M, Firozian A, Tabas somi F. The additional effect of magnesium sulphate to lidocaine in spinal anaesthesia for caesarean section. Int $\mathbf{J}$ Pharmacol 2007;3:425-7.

5. Upadya M, Pushpavathi SH, Seetharam KR. Comparison of intra-peritoneal bupivacaine and intravenous paracetamol for postoperative pain relief after laparoscopic cholecystectomy. Anesthesia, Essays and Researches. 2015;9(1):39-43.

6. Pasqualucci A, de Angelis V, Contardo R, Colò F, Terrosu G, Donini A, et al. Preemptive analgesia: Intraperitoneal local anesthetic in laparoscopic cholecystectomy. A randomized, double-blind, placebo-controlled study. Anesthesiology. 1996;85:11-20.

7. Kehlet H, Rung GW, Callesen T. Postoperative opioid analgesia: Time for a reconsideration? J Clin Anesth. 1996; 8:441-5.

8. Gvozdenovic L, Cvijanovic R, Kolak R, Pjevic M, Gavrilovic S, Veljkovic R et al. Anaesthesiology in current world of laparoscopic surgery. Med Danas. 2003;2: 298-301.

9. Marks JL, Ata B, Tulandi T. Systematic review and metaanalysis of intraperitoneal instillation of local anesthetics for reduction of pain after gynecologic laparoscopy. J Minim Invasive Gynecol. 2012;19:54553. 
10. Paulson J, Mellinger J, Baguley W. The use of intraperitoneal bupivacaine to decrease the length of stay in elective laparoscopic cholecystectomy patients. Am Surg. 2003;69:275-8.

11. Maharjan SK, Shrestha S. Intraperitoneal magnesium sulphate plus bupivacaine for pain relief after laparoscopic cholecystectomy. J Kathmandu Med Coll. 2012; $1: 21-5$.

12. Buyukakilli B, Doruk N, Çomelekoglu U, Çamdeviren H, Guneş S. Do adjuncts (tramadol and magnesium) potentiate impulse inhibition by a local anesthetic in isolated frog sciatic nerves? Turk J Med Sci. 2006;36:201-6.

13. Akinci SB, Ayhan B, Aycan IO, Tirnaksiz $\mathrm{B}$, Basgul E, Abbasoglu O, et al. The postoperative analgesic efficacy of intraperitoneal tramadol compared to normal saline or intravenous tramadol in laparoscopic cholecystectomy. Eur J Anaesthesiol. 2008;25:375-81.

14. Shukla U, Prabhakar T, Malhotra K, Srivastava D, Malhotra K. Intraperitoneal bupivacaine alone or with dexmedetomidine or tramadol for postoperative analgesia following laparoscopic cholecystectomy: A comparative evaluation. Indian J Anaesth. 2015;59:234-9.

15. Jee D, Lee D, Yun S, Lee C. Magnesium sulphate attenuates arterial pressure increase during laparoscopic cholecystectomy. Br J Anaesth. 2009;103:484-9.

16. Mentes O, Harlak A, Yigit T, Balkan A, Balkan M, Cosar A, et al. Effect of intraoperative magnesium sulphate infusion on pain relief after laparoscopic cholecystectomy. Acta Anaesthesiol Scand. 2008;52:1353-9. 